\title{
Effective PI3K modulators for improved therapy against malignant tumors and for neuroprotection of brain damage after tumor therapy (Review)
}

\author{
SATORU MATSUDA ${ }^{1 *}$, MAYUKO ICHIMURA ${ }^{1 *}$, MAKO OGINO $^{1}$, NORIKO NAKANO ${ }^{1}$, \\ AKARI MINAMI $^{1}$, TOSHIYUKI MURAI ${ }^{2}$ and YASUKO KITAGISHI ${ }^{1 *}$ \\ ${ }^{1}$ Department of Food Science and Nutrition, Nara Women's University, Kita-Uoya Nishimachi, Nara 630-8506; \\ ${ }^{2}$ Department of Microbiology and Immunology and Department of Genome Biology, \\ Graduate School of Medicine, Osaka University, Suita, Osaka 565-0871, Japan
}

Received July 26, 2016; Accepted September 15, 2016

DOI: 10.3892/ijo.2016.3710

\begin{abstract}
Due to the key role in various cellular processes including cell proliferation and cell survival on many cell types, dysregulation of the PI3K/AKT pathway represents a crucial step of the pathogenesis in many diseases. Furthermore, the tumor suppressor PTEN negatively regulates the PI3K/AKT pathway through its lipid phosphatase activity, which is recognized as one of the most frequently deleted and/or mutated genes in human cancer. Given the pervasive involvement of this pathway, the development of the molecules that modulate this PI3K/AKT signaling has been initiated in studies which focus on the extensive effective drug discovery. Consequently, the PI3K/AKT pathway appears to be an attractive pharmacological target both for cancer therapy and for neurological protection necessary after the therapy. A better understanding of the molecular relations could reveal new targets for treatment development. We review recent studies on the features of
\end{abstract}

Correspondence to: Professor Satoru Matsuda, Department of Food Science and Nutrition, Nara Women's University, Kita-Uoya Nishimachi, Nara 630-8506, Japan

E-mail:smatsuda@cc.nara-wu.ac.jp

*Contributed equally

Abbreviations: BDNF: brain-derived neurotrophic factor; DHA, docosahexaenoic acid; EPA, eicosapentaenoic acid; FABP4, fattyacid-binding protein 4; GABA, gamma-aminobutyric acid; GSK3, glycogen synthase kinase 3; HSF1, heat shock factor 1; 5-HT, 5-hydroxytryptamine, serotonin; mTOR, mammalian target of rapamycin; PIP3, phosphatidylinositol 3,4,5-triphosphate; PIP2, phosphatidylinositol 4,5-bisphosphate; PI3K, phosphoinositide-3 kinase; PTEN, phosphatase and tensin homologue deleted on chromosome 10; PPAR, peroxisome proliferator-activated receptor; PUFAs, polyunsaturated fatty acids; ROS, reactive oxygen species; SSRI, selective serotonin reuptake inhibitors

Key words: PI3K, AKT, PTEN, cell signaling, cancer, neuronal disorder
PI3K/AKT and PTEN, and their pleiotropic functions relevant to the signaling pathways involved in cancer progress and in neuronal damage by the therapy.

\section{Contents}

1. Introduction

2. PI3K/AKT/PTEN pathway is involved in cancer development

3. PI3K/AKT/PTEN pathway is involved in neurodegenera tive disorders

4. Potential therapeutic approach for neuro-cellular protection via the modulation of PI3K/AKT/PTEN pathway

5. Dietary regulation of PI3K/AKT signaling via the modified PTEN expression

6. So what next?

\section{Introduction}

Phosphatidylinositol 3-kinase (PI3K)/AKT pathway is been known as an important signaling pathway in a variety of human cancers (1-3), which also plays critical roles in normal cell survival and proliferation under physiological condition $(4,5)$. For example, prostate cancer development is often associated with silencing of the tumor suppressor phosphatase and tensin homolog (PTEN), a negative regulator of the PI3K/AKT signaling pathway $(6,7)$. The PTEN is a multi-functional enzyme inhibiting the PI3K/AKT signaling in the cytosol and stabilizing genomes in the nucleus. Various extracellular signals including growth factors and/or cell nutrients could act as modulators for the PI3K/AKT/PTEN signaling axis. Once activated PI3K recruits cellular protein kinases such as the serine/threonine kinase AKT that consecutively transduces a signal to several downstream molecules. In general, relationship of the intracellular signaling networks coordinates cellular function containing cell cycle progression, proliferation and cell protection. Mutation in some of the effectors may result in consequent activation and/or inhibition of the signaling. 


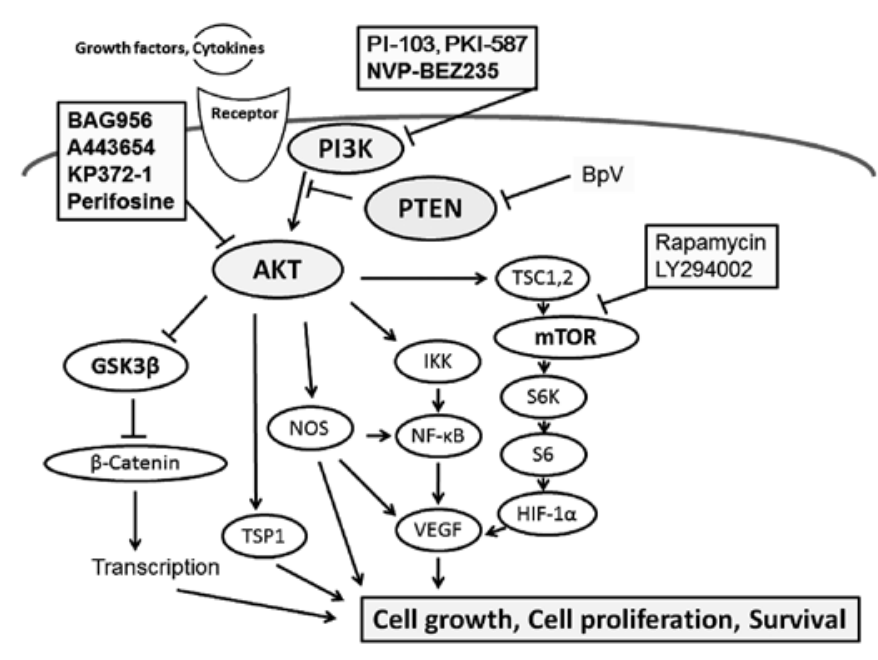

Figure 1. Schematic depiction and overview of PI3K/AKT/PTEN signaling, and example molecules known to act on the PI3K/AKT/PTEN pathway are shown. Several inhibitors linked to the PI3K/AKT/mTOR/PTEN signaling pathway are also presented. Arrowhead, indicates stimulation and hammerhead shows inhibition, suggesting implication of PI3K/AKT/mTOR modulators for pharmaceutical therapy of cancers. Note that some critical pathways have been omitted for clarity.

This dysregulation of the signal occurs commonly in many malignancies, thereby rendering the cancer cells proliferative and with survival advantage. Accordingly, both nuclear and cytosolic PTEN/PI3K/AKT activity should be reflected for correlation with clinicopathological parameters of cancer (8). In addition, the PI3K/AKT signaling has been shown to induce the gene expression of multidrug resistance protein that is considerably associated with cancer therapy-opposition (9). Development of this multidrug resistance seems the major obstacle for chemotherapy of cancers. Therefore, it seems a remarkable target for molecular therapy in various diseases including cancer and related diseases. To date, many pharmacological inhibitors acting on the PI3K/AKT pathway have been established (10).

Overall, cancer treatment could have secondary negative effects such as neurocognitive deficits, serious sequelae that follow the therapy used to treat patients especially with brain neoplasms $(11,12)$. The pathogenesis of the neurocognitive deficits involves apoptosis of neurons and other neuronal cells in a region in brain for learning and memory. After and during the intensive cancer therapy, brain damage has emerged as an important clinical problem $(13,14)$. In regards to this, some reports show that nuclear trafficking of PTEN following brain injury leads to neuronal survival (15), indicating hope for new treatment options. The present review focuses on the recent advance in PI3K/AKT/PTEN-mediated neuroprotection and neurogenesis after several cancer therapies, highlighting its potential molecular and cellular mechanisms on the therapeutic advantages.

\section{PI3K/AKT/PTEN pathway is involved in cancer development}

Increased proliferation and cell motility are common cellular consequences associated with the high levels of intra-cellular phosphatidylinositol 3,4,5-triphosphate (PIP3) that give the metastatic characteristics to cancer (16). A feedback mechanism may increase the PIP3 further activating AKT and metastasis. Therefore, several studies have advocated that the $\mathrm{PI} 3 \mathrm{~K} / \mathrm{AKT}$ signaling pathway is concerned with the progression and the prognosis of various types of cancer $(17,18)$. Accordingly, suppression of PI3K and/or AKT inhibits proliferation and induces apoptosis in cancer cells (Fig. 1). On the contrary for example, dysregulation of the PI3K/AKT pathway seems to contribute to the malignant tumor activity with RET proto-oncogene mutations (19), which are involved in the pathogenesis of some forms of a neuroendocrine medullary thyroid cancer. In addition, it has also been shown that $\mathrm{PI} 3 \mathrm{~K} / \mathrm{AKT} / \mathrm{mTOR}$ signaling may play an important role in the biology of papillary tumors (20). Positive mTOR expression and PTEN loss may have a synergic effect on tumorigenesis and cancer cell proliferation (21). The evidence may lead to possible procedures of PI3K/AKT inhibitors in the therapy for patients with certain cancers (Fig. 1). In fact, targeting PI3K/AKT signaling pathway through specific inhibitors may represent an attractive potential therapeutic approach for the patients (19), actually exhibiting potent antitumor efficacy, providing rationale for clinical investigation of this inhibition in cancers of PI3K-mediated cells (22). Classically, wortmannin and LY294002 are the most characterized PI3K/ AKT pathway inhibitors which prevent ATP from binding to the PI3Ks $(23,24)$, both of which are cell-permeable and low molecular weight compounds. Wortmannin irreversibly inhibits PI3Ks, while the inhibition with LY294002 is reversible (10). Generally, PI3K inhibitors have been discovered to affect cell growth, proliferation and survival of cancer cells, as predicted before. The PI3K/AKT and its downstream inhibitors, when combined with other pharmacological agents would appear to be a more promising therapeutic modality. Particularly, PI3K/AKT inhibitors are prominently effective in PTEN null cells (25).

\section{PI3K/AKT/PTEN pathway is involved in neuro- degenerative disorders}

ROS play a pivotal role in the pathogenesis both of neuroinflammatory and of neuro-degenerative diseases (26). Inflammatory conditions generally lead to the chronic neurodegenerative disease such as Parkinson's disease, Huntington's disease and Alzheimer's disease (27). Studies have indicated that cancer therapy commonly induces ROS production, which accelerates blood-brain barrier disruption and the neuronal cell death (28). Cancer therapy may induce apoptosis both for cancer cells and for normal neuronal cells. In this meaning, reduction of ROS may have a high potential to diminish brain damage induced during cancer therapy. It has been demonstrated that upregulation of PTEN causes modulation of PI3K/ AKT signaling pathway to reduce the ROS generation in cells (29). As described before, the PTEN is one of the most prominent tumor suppressor genes that is frequently deleted or mutated in a variety of human cancers (30). In addition, PTEN is highly expressed in neurons and it has been described to be related to critical neuroprotection $(31,32)$. Recently, it has been shown that AKT activation may likely play a therapeutic role in neurodegenerative diseases $(33,34)$. Schematic structures of the AKT and PTEN protein are shown in Fig. 2. Accordingly, 


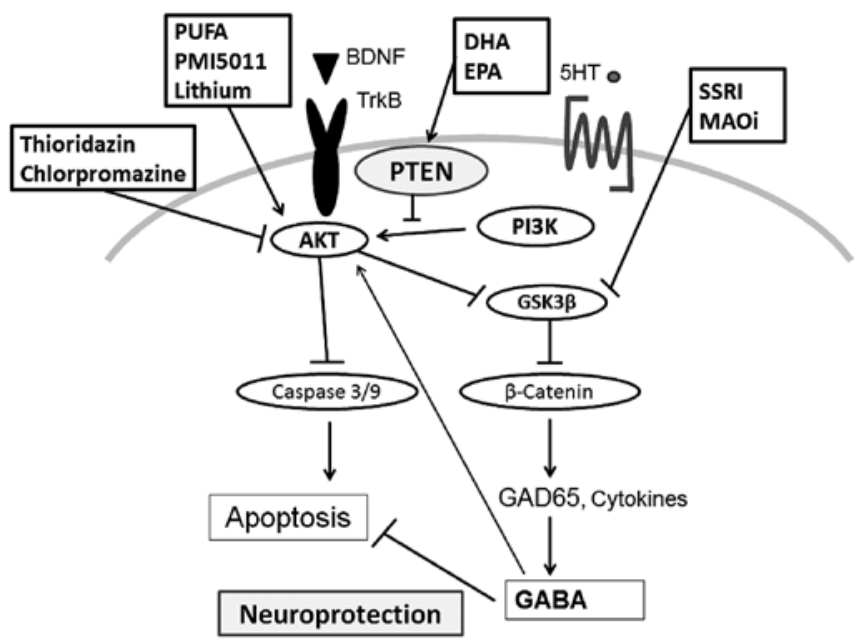

Figure 2. Potential molecular targets based on the predominant PI3K/AKT/GSK3 $\beta$ pathway, suggesting certain diets and medications may contribute to neuro-protection via modulating the function of AKT and GSK3 3 . Note that some critical events have been omitted for clarity. BDNF, brain-derived neurotrophic factor; GABA, gamma-aminobutyric acid; 5-HT, 5-hydroxytryptamine, serotonin; PUFA, polyunsaturated fatty acid; SSRI, selective serotonin reuptake inhibitors.

the tumor suppressor PTEN, which antagonizes the PI3K/ AKT pathway, has been recognized to play a crucial role in neural functions. Neuroprotection by inhibiting PTEN has been reported by activating the PI3K/AKT pathway in primary neurons $(35,36)$. Deletion of PTEN gene has been shown to result in cognitive impairment (37). Ischemic stroke induces rapid PTEN degradation in both neurons and astrocytes which play both protective and detrimental action to neurons in a spatiotemporal- and cell-type-dependent manner (38). Simultaneous deletion of PTEN promotes significant nerve regeneration after the crush injury with enhanced axon regeneration (39). However, there is somewhat controversy whether accumulation of the tumor suppressor PTEN protein under stress conditions such as trauma and stroke causes neuronal cell death. A number of studies have reported enhanced apoptosis in neurons possessing increased amount of nuclear PTEN, with the interpretation that its nuclear phosphatase activity leads to the reduction of survival AKT signaling activity. One interpretation is that brain trauma may modify the nucleo-cytoplasmic distribution of PTEN, resulting in the increased nuclear PTEN, but only in surviving neurons near the traumatic lesion $(15,40)$.

\section{Potential therapeutic approach for neuro-cellular protection via the modulation of PI3K/AKT/PTEN pathway}

Cognitive failures after brain tumor and its treatments are appropriately consistent, although there is only a small worldwide body of research describing them (41). Chemotherapy against cancer is often associated with cognitive deficits which may remain after the end of the treatment (42). In the central nervous system, PI3K/AKT signaling modifies synaptic plasticity underlying the memory-processes suggesting that PI3K/AKT signaling contributes to improvement in the cognitive development. Inhibition of PTEN is expected to promote neural cell survival, neuroprotection and neurore- generation, which can also promote myelination of axons through the AKT activation (43). Actually, a PTEN inhibitor reduces tissue damage, neuronal cell death and promotes the functional recovery (43). In addition, it has been shown that PTEN-induced putative kinase 1 (PINK1) induces mitophagy promoting neuroprotection on Huntington's disease (44). Furthermore, anti-depressants acting on serotonin neurotransmission generally activate AKT then inhibit the downstream GSK3 $\beta$ in neuronal cells. Several psychoactive medicines have been shown to modulate the activity of the PI3K/AKT signaling (45) (Fig. 2). AKT has downstream substrates such as the GSK3 $\beta$ (46). MAO inhibitors and SSRI antidepressants which promote serotonin synaptic transmission may inhibit the GSK3 $\beta$ activity (47). Atypical antipsychotics may inhibit the regulation of the GSK3 $\beta$ signaling (48). Similar results have been reported after the treatment with haloperidol $(49,50)$. Chlorpromazine is a prominent antipsychotic agent initially developed to control several psychotic disorders, which also inhibits cell proliferation and cell survival by suppressing PI3K/AKT signaling pathway (51). Whereas AKT pathway is regulated by different types of psychiatric drugs in this way, lithium activates PI3K and PI3K-dependent downstream AKT signaling (52). These activities eventually protect neuronal cells against neuronal toxicity. Therefore, treatment with inhibitors of PI3K may exacerbate neuronal cell death after brain damage in the area of injury. On the contrary, inhibition of PTEN expression diminishes the neurological damage after brain injury. In addition, it has been revealed that pharmacological inhibition of PTEN protects against brain injury in a dose-dependent manner, whose protective effect might be induced via the upregulation of PI3K/AKT signaling $(53,54)$. Furthermore, PTEN has some crosstalk effects with serotonin receptor signaling (55). By blocking dopamine D2 receptors, classic antipsychotics can prevent the inhibition of AKT signaling $(56,57)$. In addition, reductions in AKT activation in neurons may increase excitability through decreases in GABA neurotransmission (58). It seems important to exploit the potential benefits of these optimal treatments and/or combination with the PI3K/AKT modulators for the actual neuroprotection against neurological damage.

\section{Dietary regulation of PI3K/AKT signaling via the modified PTEN expression}

The PI3K/AKT and PTEN signaling plays various cellular key roles under normal and/or pathological conditions. Activation of both pathways can impact functional consequences in cancer therapy and the subsequent multiple CNS disorders. Of course, pharmacological interference of signaling molecules provides convenient method. For example, bisperoxovanadium compounds inhibit PTEN signaling, and have been used for elevation of neuroprotection in many CNS damage studies $(43,59,60)$. In addition, small molecules have prevalent use by means of experimental tools as well as therapeutics (61). Now, it is challenging to describe appropriate strategies to achieve cost effective benefits from easy diets to control the PTEN signaling molecules. Dietary and/or therapeutic interventions could not only contribute to the prevention of diseases but reduce the rate of its development. Actually, several herbs had been established to have characteristics 


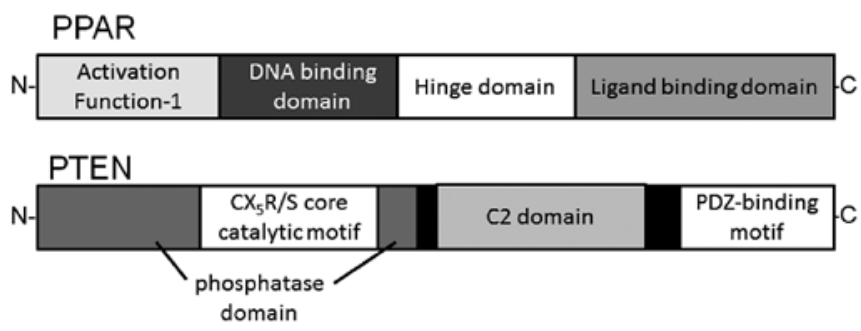

Figure 3. Schematic structures of human PPAR and PTEN protein. The predicted consensual domain structures for each protein are depicted. Note that the sizes of protein are modified for clarity. C2 domain, a structural domain involved in targeting proteins to cell membranes; PDZ, a common structural domain in signaling proteins (PSD95, Dlg, ZO-1).

for antitumor activity (62). In addition, dietary regulation of PI3K/AKT signaling via the modulating PTEN expression might be effective both for cancer inhibition and for a neuroprotection. For example, dietary intake of isothiocyanate sulforaphane, a dietary isothiocyanate derived from broccoli, modulates PTEN gene expression (63). Dietary exposure to the soy isoflavone such as genistein also induces PTEN expression at physiologically relevant concentrations (64). Phytoestrogen exposure might result in an increase in PTEN expression and the subsequent decrease in cellular responses including AKT phosphorylation. Accordingly, consumption of moderate levels of soy, vegetables, some fruits, and red wine can be protective against cancers. A high-fat diet raises circulating fatty acids, which also increases PTEN expression in prostate epithelial cells (65). In addition, dietary intake of indole-3-carbinol upregulates PTEN in an animal model (66). Indole-3-carbinol is a promising cancer-preventive phytochemical found in some vegetables such as broccoli. PTEN expression at the level of mRNA and protein is elevated in experimental animals fed with whey protein (67) which has been shown to possess multiple health benefits (67). In addition, it has been reported that DHA and EPA raise the level of PTEN in breast cancer cells, providing a mechanism for the beneficial effects of fish oils on breast cancer cells $(68,69)$. Fish oil rich in polyunsaturated fatty acids may induce the PTEN expression by activation of peroxisome proliferator-activated receptor (PPAR) $(68,69)$, which also attenuate neuron cellular damage after a brain ischemia and appear to play an important role in the activation of anti-apoptotic signaling (70). Schematic structures of human PPAR and PTEN are shown in Fig. 3. PUFA ethanolamides DHA and EPA induce autophagy through PPAR activation in cancer cells (68). In contrast, high fat diet attenuates the neuroprotection because of decreased survival of AKT signaling (71). A lignan Honokiol isolated from the bark of Magnolia officinalis could attenuate PI3K/ AKT signaling by upregulation of PTEN expression (72), which is a potential antitumor compound. Honokiol has been reported to improve the learning and memory impairments in experimental animals (73). A food ingredient curcumin, derived from the root of the plant Curcuma longa, repairs PTEN expression (74). Curcumin inhibits cell proliferation in human osteoclastoma cells (75). Furthermore, curcumin is a potential therapeutic mediator for neuro-cognition (76). In contrast, certain component of rosemary herb decreases the expression of PTEN in K562 human myeloid cells (77).
Resveratrol, an ingredient in grapes, has been reported to exhibit anticancer activity, anti-inflammatory activity and cardiovascular protection property. Notably, resveratrol has been recently reported to have neuroprotective effect (78). Supplementation of these natural compounds may provide an innovative therapeutic approach to brain disorders after cancer therapy (31).

\section{So what next?}

Increasing evidence pointing to AKT pathway-modification in psychotic disorders offer a novel implication of the treatment mechanisms for rescuing brain damage after cancer therapy. Although PTEN has been discovered as a tumor suppressor, PTEN is also involved in several other diseases, and may be regulated at multiple levels including transcription, protein stability and phosphorylation. Potential synergy with other targeted inhibitors and/or with conventional chemotherapy may provide additional therapeutic options to optimize the therapeutic efficacy. In addition, abnormalities in the PI3K/AKT signaling pathway and in the cross-talk pathways provide a clear rationale for the development of signal transduction inhibitor-based approaches aimed for both cancer therapy and the subsequent neurological disorders. Understanding the important roles of the intracellular signaling and the intricate internetwork communication is an important direction for making effective and specific therapies. However, much more work is needed to effectively produce and validate therapies that target pathways. Particularly, it will be now a challenge to seek out how to use medicinal herbs for the correction in critical processes required for maintaining neuronal homeostasis linking to a brain injury characterized by cancer therapy. Current evidence, as described here, suggests that work toward understanding these complex signaling cascades is not only promising, but may be critical for achieving the goal of improved neurological outcome after brain and spinal cord damage. This relationship has similarities with another relationship between methotrexate (MTX) therapy and a leucovorin (LV) rescue (79). We think the order of the usage of medicine and/or compound for the treatment is the most important. Of course, precise understanding of these regulations is crucial for therapeutic intervention and the effective design of novel therapeutics. A comprehensive description of the PI3K/AKT signaling network has to be evolved. Studies may be ongoing to identify the most optimal inhibitors for cancer subtypes.

\section{Acknowledgements}

The present study was supported by the JSPS KAKENHI grant number 26-12035, 24240098.

\section{References}

1. Lee JJ, Loh K and Yap YS: PI3K/Akt/mTOR inhibitors in breast cancer. Cancer Biol Med 12: 342-354, 2015.

2. Robbins HL and Hague A: The PI3K/Akt pathway in tumors of endocrine tissues. Front Endocrinol (Lausanne) 6: 188, 2016.

3. Faes S and Dormond O: PI3K and AKT: Unfaithful partners in cancer. Int J Mol Sci 16: 21138-21152, 2015.

4. Gesmundo I, Villanova T, Gargantini E, Arvat E, Ghigo E and Granata R: The mineralocorticoid agonist fludrocortisone promotes survival and proliferation of adult hippocampal progenitors. Front Endocrinol (Lausanne) 7: 66, 2016. 
5. Wahane SD, Hellbach N, Prentzell MT, Weise SC, Vezzali R, Kreutz C, Timmer J, Krieglstein K, Thedieck K and Vogel T: PI3K-p110-alpha-subtype signalling mediates survival, proliferation and neurogenesis of cortical progenitor cells via activation of mTORC2. J Neurochem 130: 255-267, 2014.

6. Simper NB, Jones CL, MacLennan GT, Montironi R, Williamson SR, Osunkoya AO, Wang M, Zhang S, Grignon DJ, Eble $\mathrm{JN}$, et al: Basal cell carcinoma of the prostate is an aggressive tumor with frequent loss of PTEN expression and overexpression of EGFR. Hum Pathol 46: 805-812, 2015.

7. Fallahabadi ZR, Noori Daloii MR, Mahdian R, Behjati F, Shokrgozar MA, Abolhasani M, Asgari M and Shahrokh H: Frequency of PTEN alterations, TMPRSS2-ERG fusion and their association in prostate cancer. Gene 575: 755-760, 2016.

8. Collaud S, Tischler V, Atanassoff A, Wiedl T, Komminoth P, Oehlschlegel C, Weder W and Soltermann A: Lung neuroendocrine tumors: Correlation of ubiquitinylation and sumoylation with nucleo-cytosolic partitioning of PTEN. BMC Cancer 15: 74, 2015.

9. Chen SY, Zheng XW, Cai JX, Zhang WP, You HS, Xing JF and Dong YL: Histone deacetylase inhibitor reverses multidrug resistance by attenuating the nucleophosmin level through PI3K/Akt pathway in breast cancer. Int J Oncol 49: 294-304, 2016.

10. Sinagra T, Tamburella A, Urso V, Siarkos I, Drago F, Bucolo C and Salomone S: Reversible inhibition of vasoconstriction by thiazolidinediones related to PI3K/Akt inhibition in vascular smooth muscle cells. Biochem Pharmacol 85: 551-559, 2013.

11. Day J, Gillespie DC, Rooney AG, Bulbeck HJ, Zienius K, Boele F and Grant R: Neurocognitive deficits and neurocognitive rehabilitation in adult brain tumors. Curr Treat Options Neurol 18: 22, 2016

12. Cheung YT and Krull KR: Neurocognitive outcomes in long-term survivors of childhood acute lymphoblastic leukemia treated on contemporary treatment protocols: A systematic review. Neurosci Biobehav Rev 53: 108-120, 2015.

13. Zheng Q, Yang L, Tan LM, Qin LX, Wang CY and Zhang HN Stroke-like migraine attacks after radiation therapy syndrome. Chin Med J (Engl) 128: 2097-2101, 2015.

14. Ricard D, Taillia H and Renard JL: Brain damage from anticancer treatments in adults. Curr Opin Oncol 21: 559-565, 2009

15. Goh CP, Putz U, Howitt J, Low LH, Gunnersen J, Bye N, Morganti-Kossmann C and Tan SS: Nuclear trafficking of Pten after brain injury leads to neuron survival not death. Exp Neurol 252: 37-46, 2014

16. Qin J, Xie Y, Wang B, Hoshino M, Wolff DW, Zhao J, Scofield MA, Dowd FJ, Lin MF and Tu Y: Upregulation of PIP3dependent Rac exchanger 1 (P-Rex1) promotes prostate cancer metastasis. Oncogene 28: 1853-1863, 2009.

17. Chen F, Chen X, Yang D, Che X, Wang J, Li X, Zhang Z, Wang Q, Zheng W, Wang L, et al: Isoquercitrin inhibits bladder cance progression in vivo and in vitro by regulating the PI3K/Akt and PKC signaling pathways. Oncol Rep 36: 165-172, 2016.

18. Zhang J, Yu XH, Yan YG, Wang C and Wang WJ: PI3K/Akt signaling in osteosarcoma. Clin Chim Acta 444: 182-192, 2015.

19. Manfredi GI, Dicitore A, Gaudenzi G, Caraglia M, Persani L and Vitale G: PI3K/Akt/mTOR signaling in medullary thyroid cancer: A promising molecular target for cancer therapy. Endocrine 48: 363-370, 2015

20. Goschzik T, Gessi M, Denkhaus D and Pietsch T: PTEN mutations and activation of the PI3K/Akt/mTOR signaling pathway in papillary tumors of the pineal region. J Neuropathol Exp Neurol 73: 747-751, 2014.

21. Han X, Ji Y, Zhao J, Xu X and Lou W: Expression of PTEN and mTOR in pancreatic neuroendocrine tumors. Tumour Biol 34: 2871-2879, 2013

22. Lee M, Wiedemann T, Gross C, Leinhäuser I, Roncaroli F, Braren R and Pellegata NS: Targeting PI3K/mTOR signaling displays potent antitumor efficacy against nonfunctioning pituitary adenomas. Clin Cancer Res 21: 3204-3215, 2015.

23. Bony C, Roche S, Shuichi U, Sasaki T, Crackower MA, Penninger J, Mano H and Pucéat M: A specific role of phosphatidylinositol 3-kinase gamma. A regulation of autonomic $\mathrm{Ca}^{2+}$ oscillations in cardiac cells. J Cell Biol 152: 717-728, 2001.

24. Yanamandra M, Mitra S and Giri A: Development and application of PI3K assays for novel drug discovery. Expert Opin Drug Discov 10: 171-186, 2015

25. Lassen A, Atefi M, Robert L, Wong DJ, Cerniglia M, CominAnduix B and Ribas A: Effects of AKT inhibitor therapy in response and resistance to BRAF inhibition in melanoma. Mol Cancer 13: 83, 2014
26. Schilling T and Eder C: Stimulus-dependent requirement of ion channels for microglial NADPH oxidase-mediated production of reactive oxygen species. J Neuroimmunol 225: 190-194, 2010

27. Clark LF and Kodadek T: The immune system and neuroinflammation as potential sources of blood-based biomarkers for Alzheimer's disease, Parkinson's disease, and Huntington's disease. ACS Chem Neurosci 7: 520-527, 2016

28. Lam M, Oleinick NL and Nieminen AL: Photodynamic therapyinduced apoptosis in epidermoid carcinoma cells. Reactive oxygen species and mitochondrial inner membrane permeabilization. J Biol Chem 276: 47379-47386, 2001.

29. Zhu Y, Hoell P, Ahlemeyer B, Sure U, Bertalanffy H and Krieglstein J: Implication of PTEN in production of reactive oxygen species and neuronal death in in vitro models of stroke and Parkinson's disease. Neurochem Int 50: 507-516, 2007.

30. Lim HJ, Crowe P and Yang JL: Current clinical regulation of PI3K/PTEN/Akt/mTOR signalling in treatment of human cancer. J Cancer Res Clin Oncol 141: 671-689, 2015.

31. Kitagishi Y and Matsuda S: Diets involved in PPAR and PI3K/ AKT/PTEN pathway may contribute to neuroprotection in a traumatic brain injury. Alzheimers Res Ther 5: 42, 2013.

32. Liu NK and Xu XM: Neuroprotection and its molecular mechanism following spinal cord injury. Neural Regen Res 7: 2051-2062, 2012

33. Cheng B, Martinez AA, Morado J, Scofield V, Roberts JL and Maffi SK: Retinoic acid protects against proteasome inhibition associated cell death in SH-SY5Y cells via the AKT pathway. Neurochem Int 62: 31-42, 2013

34. Ermak G, Hench KJ, Chang KT, Sachdev S and Davies KJ: Regulator of calcineurin (RCAN1-1L) is deficient in Huntington disease and protective against mutant huntingtin toxicity in vitro. J Biol Chem 284: 11845-11853, 2009.

35. Walker CL, Liu NK and Xu XM: PTEN/PI3K and MAPK signaling in protection and pathology following CNS injuries. Front Biol (Beijing) 8: 421-433, 2013.

36. Delgado-Esteban M, Martin-Zanca D, Andres-Martin L, Almeida A and Bolaños JP: Inhibition of PTEN by peroxynitrite activates the phosphoinositide-3-kinase/Akt neuroprotective signaling pathway. J Neurochem 102: 194-205, 2007.

37. Takeuchi K, Gertner MJ, Zhou J, Parada LF, Bennett MV and Zukin RS: Dysregulation of synaptic plasticity precedes appearance of morphological defects in a Pten conditional knockout mouse model of autism. Proc Natl Acad Sci USA 110: 4738-4743, 2013.

38. Li W, Huang R, Chen Z, Yan LJ, Simpkins JW and Yang SH: PTEN degradation after ischemic stroke: A double-edged sword. Neuroscience 274: 153-161, 2014.

39. Sun F, Park KK, Belin S, Wang D, Lu T, Chen G, Zhang K, Yeung C, Feng G, Yankner BA, et al: Sustained axon regeneration induced by co-deletion of PTEN and SOCS3. Nature 480: 372-375, 2011.

40. Li Y, Low LH, Putz U, Goh CP, Tan SS and Howitt J: Rab5 and Ndfipl are involved in Pten ubiquitination and nuclear trafficking. Traffic 15: 749-761, 2014.

41. Mandelblatt JS, Hurria A, McDonald BC, Saykin AJ, Stern RA, VanMeter JW, McGuckin M, Traina T, Denduluri N, Turner S, et al; Thinking and Living With Cancer Study: Cognitive effects of cancer and its treatments at the intersection of aging: What do we know; what do we need to know? Semin Oncol 40: 709-725, 2013.

42. Evenden J: Cognitive impairments and cancer chemotherapy: Translational research at a crossroads. Life Sci 93: 589-595, 2013.

43. Walker CL and Xu XM: PTEN inhibitor bisperoxovanadium protects oligodendrocytes and myelin and prevents neuronal atrophy in adult rats following cervical hemicontusive spinal cord injury. Neurosci Lett 573: 64-68, 2014.

44. Khalil B, El Fissi N, Aouane A, Cabirol-Pol MJ, Rival T and Liévens JC: PINK1-induced mitophagy promotes neuroprotection in Huntington's disease. Cell Death Dis 6: e1617, 2015.

45. Ozaita A, Puighermanal E and Maldonado R: Regulation of PI3K/ Akt/GSK-3 pathway by cannabinoids in the brain. J Neurochem 102: 1105-1114, 2007.

46. Li S, Zhou Y, Wang R, Zhang H, Dong Y and Ip C: Selenium sensitizes MCF-7 breast cancer cells to doxorubicin-induced apoptosis through modulation of phospho-Akt and its downstream substrates. Mol Cancer Ther 6: 1031-1038, 2007.

47. Hui J, Zhang J, Kim H, Tong C, Ying Q, Li Z, Mao X, Shi G, Yan J, Zhang Z, et al: Fluoxetine regulates neurogenesis in vitro through modulation of GSK- $3 \beta / \beta$-catenin signaling. Int $\mathbf{J}$ Neuropsychopharmacol 18: pyu099, 2014. 
48. Park SW, Phuong VT, Lee CH, Lee JG, Seo MK, Cho HY, Fang ZH, Lee BJ and Kim YH: Effects of antipsychotic drugs on BDNF, GSK-3 $\beta$, and $\beta$-catenin expression in rats subjected to immobilization stress. Neurosci Res 71: 335-340, 2011.

49. Emamian ES, Hall D, Birnbaum MJ, Karayiorgou M and Gogos JA: Convergent evidence for impaired AKT1-GSK3beta signaling in schizophrenia. Nat Genet 36: 131-137, 2004.

50. Kozlovsky N, Amar S, Belmaker RH and Agam G: Psychotropic drugs affect Ser9-phosphorylated GSK-3 beta protein levels in rodent frontal cortex. Int J Neuropsychopharmacol 9: 337-342, 2006.

51. Shin SY,Lee KS, Choi YK, Lim HJ, Lee HG, Lim Y and Lee YH: The antipsychotic agent chlorpromazine induces autophagic cell death by inhibiting the Akt/mTOR pathway in human U-87MG glioma cells. Carcinogenesis 34: 2080-2089, 2013.

52. Liu KJ, Lee YL, Yang YY, Shih NY, Ho CC, Wu YC, Huang TS, Huang MC, Liu HC, Shen WW, et al: Modulation of the development of human monocyte-derived dendritic cells by lithium chloride. J Cell Physiol 226: 424-433, 2011.

53. Wu J, Li J, Hu H, Liu P, Fang Y and Wu D: Rho-kinase inhibitor fasudil, prevents neuronal apoptosis via the Akt activation and PTEN inactivation in the ischemic penumbra of rat brain. Cell Mol Neurobiol 32: 1187-1197, 2012.

54. Liu B, Li L, Zhang Q, Chang N, Wang D, Shan Y, Li L, Wang H, Feng H, Zhang L, et al: Preservation of GABAA receptor function by PTEN inhibition protects against neuronal death in ischemic stroke. Stroke 41: 1018-1026, 2010.

55. Cai J, Yi Z, Lu W, Fang Y and Zhang C: Crosstalk between 5-HT2cR and PTEN signaling pathway in atypical antipsychoticinduced metabolic syndrome and cognitive dysfunction. Med Hypotheses 80: 486-489, 2013.

56. Mirones I, Angel Rodríguez-Milla M, Cubillo I, MariñasPardo L, de la Cueva T, Zapata A, González C, Ramírez M and García-Castro J: Dopamine mobilizes mesenchymal progenitor cells through D2-class receptors and their PI3K/AKT pathway. Stem Cells 32: 2529-2538, 2014.

57. Stavarache MA, Musatov S, McGill M, Vernov M and Kaplitt MG: The tumor suppressor PTEN regulates motor responses to striatal dopamine in normal and Parkinsonian animals. Neurobiol Dis 82: 487-494, 2015.

58. Souza BR, Romano-Silva MA and Tropepe V: Dopamine D2 receptor activity modulates Akt signaling and alters GABAergic neuron development and motor behavior in zebrafish larvae. J Neurosci 31: 5512-5525, 2011.

59. Walker CL, Walker MJ, Liu NK, Risberg EC, Gao X, Chen J and Xu XM: Systemic bisperoxovanadium activates Akt/mTOR, reduces autophagy, and enhances recovery following cervical spinal cord injury. PLoS One 7: e30012, 2012.

60. Mao D and Sun X: Reactivation of the PI3K/Akt signaling pathway by the bisperoxovanadium compound $\mathrm{bpV}$ (pic) attenuates photoreceptor apoptosis in experimental retinal detachment. Invest Ophthalmol Vis Sci 56: 5519-5532, 2015.

61. Spinelli L, Lindsay YE and Leslie NR: PTEN inhibitors: an evaluation of current compounds. Adv Biol Regul 57: 102-111, 2015.

62. Tian HY, Li ZX, Li HY, Wang HJ, Zhu XW and Dou ZH: Effects of 14 single herbs on the induction of caspase-3 in tumor cells: A brief review. Chin J Integr Med 19: 636-640, 2013.

63. Traka MH, Spinks CA, Doleman JF, Melchini A, Ball RY, Mills RD and Mithen RF: The dietary isothiocyanate sulforaphane modulates gene expression and alternative gene splicing in a PTEN null preclinical murine model of prostate cancer. Mol Cancer 9: 189, 2010.

64. de la Parra C, Castillo-Pichardo L, Cruz-Collazo A, Cubano L, Redis R, Calin GA and Dharmawardhane S: Soy isoflavone genistein-mediated downregulation of miR-155 contributes to the anticancer effects of genistein. Nutr Cancer 68: 154-164, 2016.
65. Kwon OJ, Zhang B, Zhang L and Xin L: High fat diet promotes prostatic basal-to-luminal differentiation and accelerates initiation of prostate epithelial hyperplasia originated from basal cells. Stem Cell Res (Amst) 16: 682-691, 2016.

66. Aronchik I, Kundu A, Quirit JG and Firestone GL: The antiproliferative response of indole-3-carbinol in human melanoma cells is triggered by an interaction with NEDD4-1 and disruption of wild-type PTEN degradation. Mol Cancer Res 12: 1621-1634, 2014.

67. Eason RR, Velarde MC, Chatman L Jr, Till SR, Geng Y, Ferguson M, Badger TM and Simmen RC: Dietary exposure to whey proteins alters rat mammary gland proliferation, apoptosis, and gene expression during postnatal development. J Nutr 134: 3370-3377, 2004

68. Rovito D, Giordano C, Vizza D, Plastina P, Barone I, Casaburi I, Lanzino M, De Amicis F, Sisci D, Mauro L, et al: Omega-3 PUFA ethanolamides DHEA and EPEA induce autophagy through PPAR $\gamma$ activation in MCF-7 breast cancer cells. J Cell Physiol 228: 1314-1322, 2013

69. Ghosh-Choudhury T, Mandal CC, Woodruff K, St Clair P, Fernandes G, Choudhury GG and Ghosh-Choudhury N: Fish oil targets PTEN to regulate NFkappaB for downregulation of antiapoptotic genes in breast tumor growth. Breast Cancer Res Treat 118: 213-228, 2009.

70. Moreira JD, Knorr L, Thomazi AP, Simão F, Battú C, Oses JP, Gottfried C, Wofchuk S, Salbego C, Souza DO, et al: Dietary omega-3 fatty acids attenuate cellular damage after a hippocampal ischemic insult in adult rats. J Nutr Biochem 21: 351-356, 2010.

71. Yu H, Deng J and Zuo Z: High-fat diet reduces neuroprotection of isoflurane post-treatment: Role of carboxyl-terminal modulator protein-Akt signaling. Obesity (Silver Spring) 22: 2396-2405, 2014.

72. Liu H, Zang C, Emde A, Planas-Silva MD, Rosche M, Kühnl A, Schulz CO, Elstner E, Possinger K and Eucker J: Anti-tumor effect of honokiol alone and in combination with other anticancer agents in breast cancer. Eur J Pharmacol 591: 43-51, 2008.

73. Xian YF, Ip SP, Mao QQ, Su ZR, Chen JN, Lai XP and Lin ZX: Honokiol improves learning and memory impairments induced by scopolamine in mice. Eur J Pharmacol 760: 88-95, 2015

74. Wong TF, Takeda T, Li B, Tsuiji K, Kitamura M, Kondo A and Yaegashi N: Curcumin disrupts uterine leiomyosarcoma cells through AKT-mTOR pathway inhibition. Gynecol Oncol 122: $141-148,2011$

75. Cao F, Liu T, Xu Y, Xu D and Feng S: Curcumin inhibits cell proliferation and promotes apoptosis in human osteoclastoma cell through MMP-9, NF- $\kappa \mathrm{B}$ and JNK signaling pathways. Int J Clin Exp Pathol 8: 6037-6045, 2015.

76. Hoppe JB, Coradini K, Frozza RL, Oliveira CM, Meneghetti AB, Bernardi A, Pires ES, Beck RC and Salbego CG: Free and nanoencapsulated curcumin suppress $\beta$-amyloid-induced cognitive impairments in rats: Involvement of BDNF and Akt/GSK-3 $\beta$ signaling pathway. Neurobiol Learn Mem 106: 134-144, 2013.

77. Yoshida H, Okumura N, Kitagishi Y, Nishimura Y and Matsuda S: Ethanol extract of Rosemary repressed PTEN expression in K562 culture cells. Int J appl Biol Pharm Technol 2: 316-322, 2011.

78. Choi SY, Kim YO, Son D, Lee J, Kim S, Kim H, Kim S and Hur J: 3-[2-(3,5-Dimethoxyphenyl)vinyl]furan protects hippocampal neurons against ischemic damage. Brain Res 1472: 32-37, 2012.

79. Tedeschi PM, Kathari YK, Farooqi IN and Bertino JR: Leucovorin rescue allows effective high-dose pralatrexate treatment and an increase in therapeutic index in mesothelioma xenografts. Cancer Chemother Pharmacol 74: 1029-1032, 2014. 